\title{
BMJ Open Prevalence and determinants of breast cancer screening in four sub-Saharan African countries: a population- based study
}

\author{
Djibril M Ba (D) , ${ }^{1}$ Paddy Ssentongo (D) , ${ }^{1}$ Edeanya Agbese, ${ }^{1}$ Yanxu Yang (D) , \\ Ramata Cisse, ${ }^{2}$ Brehima Diakite, ${ }^{3}$ Cheick Bougadari Traore, ${ }^{3}$ Bakarou Kamate, ${ }^{3}$ \\ Yaya Kassogue, ${ }^{3}$ Guimogo Dolo, ${ }^{3}$ Etienne Dembele, ${ }^{4}$ Hama Diallo, ${ }^{3}$ \\ Mamoudou Maiga ${ }^{4}$
}

To cite: Ba DM, Ssentongo P, Agbese E, et al. Prevalence and determinants of breast cancer screening in four sub-Saharan African countries: a populationbased study. BMJ Open 2020;10:e039464. doi:10.1136/ bmjopen-2020-039464

- Prepublication history for this paper is available online. To view these files, please visit the journal online (http://dx.doi org/10.1136/bmjopen-2020039464).

Received 17 April 2020 Revised 19 August 2020 Accepted 20 August 2020

Check for updates

(C) Author(s) (or their employer(s)) 2020. Re-use permitted under CC BY-NC. No commercial re-use. See rights and permissions. Published by BMJ.

${ }^{1}$ Department of Public Health Sciences, Penn State College of Medicine, Hershey, Pennsylvania, USA

${ }^{2}$ Department of Psychology, Stony Brook University, Stony Brook, New York, USA

${ }^{3}$ Faculty of Medicine and Odontostomatology, University of Sciences Techniques and Technologies of Bamako, Bamako, Mali

${ }^{4}$ Department of Biomedical Engineering, Northwestern University, Evanston, Illinois, USA

Correspondence to

Dr Djibril M Ba;

djibrilba@phs.psu.edu

\section{ABSTRACT}

Objectives Breast cancer is the most prevalent cancer and the second leading cause of cancer-related deaths among women after cervical cancer in much of sub-Saharan Africa. This study aims to examine the prevalence and sociodemographic-socioeconomic factors associated with breast cancer screening among women of reproductive age in sub-Saharan Africa.

Design A weighted population-based cross-sectional study using Demographic and Health Surveys (DHS) data. We used all available data on breast cancer screening from the DHS for four sub-Saharan African countries (Burkina Faso, Ivory Coast, Kenya and Namibia). Breast cancer screening was the outcome of interest for this study. Multivariable Poisson regression was used to identify independent factors associated with breast cancer screening.

Setting Four countries participating in the DHS from 2010 to 2014 with data on breast cancer screening.

Participants Women of reproductive age 15-49 years ( $\mathrm{N}=39646)$.

Results The overall prevalence of breast cancer screening was only $12.9 \%$ during the study period, ranging from $5.2 \%$ in Ivory Coast to $23.1 \%$ in Namibia. Factors associated with breast cancer screening were secondary/higher education with adjusted prevalence ratio (adjusted PR)=2.33 (95\% Cl: 2.05 to 2.66) compared with no education; older participants, 35-49 years (adjusted $\mathrm{PR}=1.73,95 \% \mathrm{Cl}: 1.56$ to 1.91 ) compared with younger participants 15-24 years; health insurance coverage (adjusted PR=1.57, 95\% Cl: 1.47 to 1.68) compared with those with no health insurance and highest socioeconomic status (adjusted $\mathrm{PR}=1.33,95 \% \mathrm{Cl}: 1.19$ to 1.49 ) compared with lowest socioeconomic status.

Conclusion Despite high breast cancer mortality rates in sub-Saharan Africa, the prevalence of breast cancer screening is substantially low and varies gradually across countries and in relation to factors such as education, age, health insurance coverage and household wealth index level. These results highlight the need for increased efforts to improve the uptake of breast cancer screening in subSaharan Africa.
Strengths and limitations of this study

- We conducted a large population-based crosssectional study of more than 39000 women of reproductive age in four sub-Saharan African countries.

- This is one of only a few studies to investigate the prevalence and determinants of breast cancer screening across multiple countries in sub-Saharan Africa.

- The results of this study provide useful information for programmatic efforts to increase breast cancer screening in sub-Saharan Africa and ultimately to prevent breast cancer-related deaths.

- The cross-sectional nature of the survey does not allow for the determination of temporal relationships.

- This study was limited to only 4 of the 48 countries in sub-Saharan Africa.

\section{INTRODUCTION}

Breast cancer is the most commonly occurring cancer and the leading cause of cancer deaths among women globally. ${ }^{1}$ In 140 out of 184 countries in the world, breast cancer is the most diagnosed form of cancer. $^{2}$ In 2018, breast cancer ranked second after lung cancer in all cancer cases with 2088849 cases (accounting for $11.6 \%$ of all new cases for all ages) globally. In terms of mortality rates, breast cancer ranked fourth with 626679 deaths (accounting for $6.6 \%$ of all cancer-related deaths globally). ${ }^{3}$ Conversely in 2018, the number of new breast cancer cases among females of all ages in Africa was $27.7 \%$ (168 690/608 616), which is 1.5 times the cases of prostate cancer in the region (18.1\% (80 971/446 556)). ${ }^{4}$ Most countries in sub-Saharan Africa (SSA) are focused on combating communicable diseases such as tuberculosis and HIV/AIDS, and as such, noncommunicable diseases such as cancers are 
low priority leading to a lack of breast cancer screening. ${ }^{56}$ Breast cancer screening plays a significant role in the early detection of breast cancer, increases treatment options for affected women and improves cancer survival rates. ${ }^{7}$ Delays in breast cancer detection in SSA contribute to high mortality and poor quality of life ${ }^{58}$ Low and middleincome countries (LMICs) including SSA have disproportionally low 5-year survival rates of breast cancer of about $53 \%$ compared with over $85 \%$ in high-income countries (HICs) such as USA. ${ }^{9}$ Higher survival rates of breast cancer in HICs over the past 25 years have been associated with improved adjuvant systemic therapy and advanced early detection via mammography, which is the only breast cancer screening ever shown in randomised controlled trials to reduce breast cancer-specific mortality by $15 \%-30 \% .^{10-14}$ This is in contrast to LMICs such as much of SSA with very limited resources where mammography screening is not yet available on a population-based level. ${ }^{15}$

The major attributable factors to a low survival rate of breast cancer in SSA include late-stage diagnosis and lack of access to quality healthcare.$^{516-19}$ In 2018, a study conducted at Kenyatta Hospital indicated that $7.4 \%$ of women were diagnosed in tumour stage I, $33.7 \%$ in stage II, $29.7 \%$ in stage III and $21 \%$ in stage IV. ${ }^{19}{ }^{20} \mathrm{~A}$ study conducted by Gebremariam et al indicated that patients with breast cancer in Addis Ababa had prolonged patient and diagnostic intervals. ${ }^{21}$ In addition to these contributing factors, the prevalence of breast cancer is underreported in most SSA countries and is not a true reflection of the burden of the disease. ${ }^{1618}$ To tailor strategies to increase the uptake of breast cancer screening among women of reproductive age in SSA, it is important to understand regional-specific and country-specific variations in the prevalence of breast cancer screening. Such knowledge will guide the prioritisation of intervention strategies to the most at-risk countries in SSA and help countries better understand potential reasons for the low prevalence of breast cancer screening. These estimates are missing because most of the previous studies regarding breast cancer screening in SSA have focused mainly on individual countries such as Namibia and Kenya using Demographic and Health Surveys data (DHS) ${ }^{6}{ }^{22}$ Thus, we aimed to fill this knowledge gap by conducting a largescale study of breast cancer screening in four combined SSA countries and associated sociodemographic-socioeconomic factors using all available DHS data from 2010 to 2014 .

\section{METHODS}

\section{Data source and participants}

The present study included all SSA countries that participated in the DHS from 2010 to 2014 and collected data about breast cancer screening among women. The DHS are nationally representative data and funded by the U.S. Agency for International Development and are implemented by ICF International and the government of the host countries. Four countries with available data on breast cancer screening in SSA were included in the analysis. These countries were: Burkina Faso, Ivory Coast, Kenya and Namibia each contributing 1 year of survey data. The survey in each country was conducted using face-to-face questionnaire interviews and used multistage cluster sampling, stratified design to collect information about demographics and population health status, health behaviours, neonatal mortality, nutritional status and family planning in each country. ${ }^{23}{ }^{24}$ The year of the administration of the relevant DHS for each country can be seen in table 1 .

\section{Ethical considerations}

A written request was sent to the DHS program and permission was granted to download and use the data from http://www.dhsprogram.com. Each country's procedures and questionnaires for standard DHS were reviewed and

Table 1 Weighted sample size, prevalence of breast cancer screening and multivariable-adjusted prevalence ratio (aPR) by country and survey year $(\mathrm{N}=39646)$

\begin{tabular}{|c|c|c|c|c|c|}
\hline \multirow[b]{2}{*}{ Countries } & \multirow[b]{2}{*}{ Survey year } & \multirow{2}{*}{$\begin{array}{l}\text { All participants } \\
N^{*}(\% \dagger) \\
\end{array}$} & \multirow{2}{*}{$\begin{array}{l}\text { Breast cancer } \\
\text { screening } \\
\mathrm{N} \neq(\%) \\
\end{array}$} & \multicolumn{2}{|c|}{ Multivariable-adjusted analysis } \\
\hline & & & & aPR $(95 \% \mathrm{Cl})$ & $P$ value \\
\hline Overall & & 39646 & 5128 (12.9) & & \\
\hline Burkina Faso & 2010 & $9534(24.1)$ & $713(7.5)$ & 1.58 (1.32 to 1.89$)$ & $<0.001$ \\
\hline Ivory Coast & $2011-12$ & $6402(16.2)$ & $331(5.2)$ & ref. & \\
\hline Kenya & 2014 & $14579(36.8)$ & 1979 (13.6) & $1.92(1.67$ to 2.21$)$ & $<0.001$ \\
\hline Namibia & 2013 & $9131(23.0)$ & 2105 (23.1) & 3.33 (2.90 to 3.83 ) & $<0.001$ \\
\hline
\end{tabular}

Model fully adjusted for country, health insurance coverage pregnancy status, breastfeeding status, age, education status, marital status, wealth index status, place of residence, employment status, number of living children, household having a radio or television and visited healthcare facility in the last 12 months.

*Weighted sample size of the combined dataset that is represented by that survey for each country.

†The per cent of the combined dataset that is represented by that survey.

$\ddagger$ Breast cancer screening rate.

ref., reference. 
approved by the ICF Institutional Review Board (IRB) and the IRBs of the host countries. Written or oral informed consent was obtained from each participant before the survey. Survey respondents were not coerced into participation $^{25}$ and all data are the Health Insurance Portability and Accountability Act protected and completely deidentified with no names or household addresses in the data files. The ethical matters were handled by the ICF IRB and the IRBs of the four host countries (Burkina Faso, Ivory Coast, Kenya and Namibia) who conducted the primary surveys and not by the authors of this article. Therefore, no further IRB approval was needed by the institutions of the authors of this manuscript. Details on the ethical matters are described elsewhere. ${ }^{26}$

\section{Patient and public involvement}

Patients and the public were not involved in the design or planning of this secondary data analysis. The data were extracted directly from the DHS program database and do not contain any personally identifiable information.

\section{Assessment of breast cancer screening (outcome)}

Respondent women were asked during the survey whether they had ever been screened for breast cancer prior to the survey and was measured using questions: 'Have you ever had a breast cancer screening?', 'Has a doctor or other health professional examined your breast to detect or check for breast cancer?'. Screening options include: clinical breast examination, ultrasound or mammography. Detailed information on the breast cancer screening questionnaires are described elsewhere. ${ }^{27}$ The binary response of breast cancer screening (yes/no) was used as our dependent variable as done by previous researchers using DHS data. ${ }^{622}$ Women with a missing value for breast cancer examination or who did not know about their screening status were excluded from this study.

\section{Assessment of potential sociodemographic factors}

We examined the following factors to see whether they were associated with breast cancer screening: health insurance coverage, age, wealth index status, education status, marital status, place of residence, employment status, number of living children, household owning a radio, household owning a television and visited healthcare facility in the last 12 months. ${ }^{28}$ Previous studies reported that these sociodemographic-socioeconomic factors may affect women's breast cancer screening behaviours. ${ }^{62}$ We recategorised wealth index from five quintiles into three categories by combining poorest and poorer into one category (called 'lowest'); middle wealth level into the second category (called 'middle) and richer and richest into the third category (called 'highest), as previous researchers have done. ${ }^{29-31}$ The age of survey respondents at the time of the DHS interview was originally measured as a continuous variable and we recategorised age into three groups for this study (15-24, 25-34 and 35-49 years old).

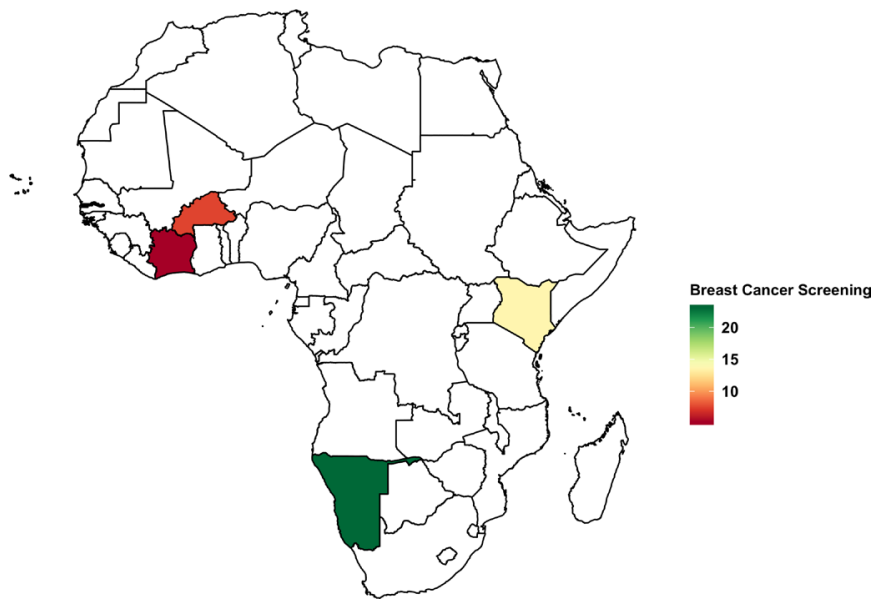

Figure 1 Weighted prevalence of breast cancer screening in sub-Saharan Africa (\%) in women of reproductive age 15-49 years shaded by sub-Saharan countries in Africa. Countries shaded white were not included in the analysis.

\section{Statistical analysis}

We extracted breast cancer screening questionnaires from individual women's data for each country. The data from the four countries were then combined into a single analytical dataset. Following the DHS program recommendation for the analysis of DHS data, we used an appropriate weight for each analysis, based on the variable selected. ${ }^{32}$ Univariate analyses were conducted using frequency distributions for categorical variables to describe the characteristics of the study population. We calculated the prevalence of breast cancer screening among women as the number of women who had breast cancer screening divided by the total number of women interviewed in that category and multiplied by 100 . The multivariable analysis included generalised estimating equations with an independent correlation structure to identify factors associated with breast cancer. To specify the use of the robust variance estimator for Poisson regression, the REPEATED statement (in SAS) was used by accounting for each country-specific primary sampling unit (PSU).$^{33}$ Descriptive results are presented as the prevalence of breast cancer screening and the multivariable Poisson regression results are presented as adjusted prevalence ratios (adjusted PRs) with 95\% CIs. We controlled for the country in the adjusted PR analyses.

Analyses were conducted using SAS V.9.4 (SAS Institute) and V.R-3.4.3 to generate figure 1. Statistical tests were reported as significant at $\mathrm{p}$ values less than 0.05 . Ivory Coast was selected as the reference country because it was the country with the lowest rate of breast cancer screening.

\section{RESULTS}

\section{Sociodemographic characteristics of the respondents}

Among 39646 participants in the current analysis, the mean (SD) age was 29.1 (9.3) years. About $90 \%$ of the study participants did not have health insurance coverage 
$(88.3 \%)$. The majority of the respondents were from a wealthy household $(51.5 \%)$ and approximately $43.0 \%$ of women had secondary/higher education. More than one-third of the respondents were young between the ages of 15 and 24 years $(37.5 \%)$. In addition, more than half of the survey respondents were married/living with a partner $(58.0 \%)$, resided in rural areas $(52.4 \%)$, were currently employed $(61.3 \%)$ or visited a healthcare facility in the last 12 months (59.7\%). Women with one or more living children less than 5 years old at the time of the DHS interview constituted $59.7 \%$ of the survey respondents. More than half of the women had a radio in the household $(68.2 \%)$ but most did not have a television $(58.8 \%)$.

\section{The prevalence of breast cancer screening in SSA}

The overall prevalence of breast cancer screening was only $12.9 \%$ with $95 \% \mathrm{CI}$ : $(12.6 \%$ to $13.3 \%)$ during the study period, ranging from $5.2 \%$ in Ivory Coast to $23.1 \%$ in Namibia (table 1 and figure 1). The rate of breast cancer screening was higher among women who had health insurance coverage $(33.1 \%)$, secondary/ higher education $(19.5 \%)$ or were in wealthy households $(16.8 \%)$. In addition, breast cancer screening was more common among women who had access to a television or radio in the household ( $18.4 \%$ and $14.2 \%$, respectively) compared with those without such items. Women living in urban areas had a higher rate of breast cancer screening $(17.6 \%)$ compared with those living in rural areas $(8.7 \%)$ (table 1).

\section{Independent factors associated with breast cancer screening}

The country of residence was the factor most strongly associated with breast cancer screening in this study (table 1). Countries with the highest prevalence of breast cancer screening were Namibia followed by Kenya, Burkina Faso and Ivory Coast. Women's education level was an important factor associated with breast cancer screening (table 2). Women with secondary/higher education were 2.33 times more likely to undergo breast cancer screening (adjusted PR=2.33, 95 CI: 2.05 to 2.66) compared with no education. Furthermore, a dose-response relationship was evident between age and breast cancer screening, where increasing age was positively associated with a higher breast cancer screening rate $(\mathrm{p}$ trend $<0.0001)$. Older participants aged 35-49 years were $73 \%$ more likely to be screened for breast cancer (adjusted PR $=1.73,95 \%$ CI: 1.56 to 1.91 ) compared with younger participants aged 15-24 years. Having health insurance coverage was positively associated with breast cancer screening (adjusted $\mathrm{PR}=1.57,95 \% \mathrm{CI}: 1.47$ to 1.68 ) compared with those with no health insurance. Women in the highest socioeconomic status were $33 \%$ more likely to undergo breast cancer screening (adjusted PR=1.33, 95\% CI: 1.19 to 1.49) compared with those in the lowest socioeconomic status. Possession of television was positively associated with breast cancer screening (adjusted $\mathrm{PR}=1.17,95 \% \mathrm{CI}$ : 1.08 to 1.27 ) compared with those with no television.

\section{DISCUSSION}

This population-based cross-sectional study of more than 39000 women of reproductive age in SSA assessed the prevalence of breast cancer screening and its associated sociodemographic determinants. Our study indicated heterogeneity and disparities in the prevalence of breast cancer screening across SSA countries. The overall prevalence of breast cancer screening in SSA was only $12.9 \%$ during the study period. The low prevalence of breast cancer screening in our study was not surprising and is consistent with a previous study that also found that $86 \%$ of women in western Kenya had not undergone breast cancer screening previously. ${ }^{34}$

While mammogram is a well-established advanced screening method for the early detection of breast cancer with higher survival rates in HICs, implementing this screening services can be cost-prohibitive and may not be feasible in much of SSA countries. ${ }^{35}$ In most HICs, mammograms are typically recommended for women over the age of 40 and is included as part of preventive care thus, making it available to most women. ${ }^{12}{ }^{36}$ In contrast, most countries in SSA lack national screening programmes and have insufficient funds to screen all eligible women. ${ }^{1236}$ Despite scarce financial resources, the Cancer Association of South Africa guidelines advocate for a mammogram every year for all women aged 40 years and older for the purpose of asymptomatic breast cancer screening and recommends discussion of any breast health problems with primary healthcare providers. ${ }^{12} 36$

In the absence of mammographic screening in most LMICs including SSA due to a lack of financial, human and poor physical resources, screening clinical breast examination every year for women younger than age 40 years may be an effective method to detect more early signs of breast cancer in these areas. ${ }^{35}$ 37-40 Previous studies have shown that one-fifth of breast cancer cases in LMICs occur in women aged $30-40$ years ${ }^{3741} 42$, and a South African study showed that more than 1370 women diagnosed with breast cancer in 2011 in the country were between 20 and 44 years. ${ }^{36}$ In addition, a previous study has also indicated that only $2.2 \%$ of women aged 40-69 years in developing countries (including SSA countries) had received breast cancer screening in the past 5 years. ${ }^{43}$ These findings support a modified screening strategy in LMICs . Moreover, a previous study conducted in Northeast Africa (Sudan) suggested that clinical breast examination using local community volunteers could also increase early detection of breast cancer in asymptomatic women. ${ }^{44}$

Findings from this study indicated that there are substantial variations in the prevalence of breast cancer screening across these four countries. These findings underscore the potentially clinical and public health implications because screening for early detection plays a significant role in the control and prevention of breast cancer, which could improved survivorship. ${ }^{19}$ The 2018 Kenyan National screening guideline recommended that screening clinical breast examination should be 
Table 2 Background characteristics of the weighted survey participants, prevalence of breast cancer screening and multivariable-adjusted prevalence ratio (aPR) $(\mathrm{N}=39646)$

\begin{tabular}{|c|c|c|c|c|}
\hline \multirow[b]{2}{*}{ Characteristic } & All participants & $\begin{array}{l}\text { Breast cancer } \\
\text { screening }\end{array}$ & $\begin{array}{l}\text { Multivariable-adjusted } \\
\text { analysis }\end{array}$ & \multirow[b]{2}{*}{$P$ value } \\
\hline & $\mathrm{N}(\%)$ & $\mathbf{N}(\%)$ & aPR $(95 \% \mathrm{Cl})$ & \\
\hline \multicolumn{5}{|l|}{ Age group (years) } \\
\hline $15-24$ & $14856(37.5)$ & $1123(7.6)$ & ref. & \\
\hline $25-34$ & $13342(33.7)$ & $2032(15.2)$ & 1.41 (1.29 to 1.54$)$ & $<0.001$ \\
\hline $35-49$ & $11448(28.9)$ & $1973(17.2)$ & 1.73 (1.56 to 1.91$)$ & $<0.001$ \\
\hline \multicolumn{5}{|l|}{ Health insurance } \\
\hline No & $34990(88.3)$ & 3588 (10.3) & ref. & \\
\hline Yes & $4647(11.7)$ & $1537(33.1)$ & 1.57 (1.47 to 1.68$)$ & $<0.001$ \\
\hline \multicolumn{5}{|l|}{ Wealth index status } \\
\hline Lowest & $12093(30.5)$ & $933(7.7)$ & ref. & \\
\hline Middle & $7151(18.0)$ & 776 (10.9) & 1.18 (1.07 to 1.31$)$ & 0.001 \\
\hline Highest & $20402(51.5)$ & 3419 (16.8) & 1.33 (1.19 to 1.49$)$ & $<0.001$ \\
\hline \multicolumn{5}{|l|}{ Place of residence } \\
\hline Urban & $18869(47.6)$ & 3312 (17.6) & ref. & \\
\hline Rural & $20777(52.4)$ & $1816(8.7)$ & $0.78(0.72$ to 0.85$)$ & $<0.001$ \\
\hline \multicolumn{5}{|l|}{ Education } \\
\hline No education & $10080(25.4)$ & $497(4.9)$ & ref. & \\
\hline Primary & $12540(31.6)$ & 1305 (10.4) & 1.77 (1.56 to 2.01$)$ & $<0.001$ \\
\hline Secondary/higher & $17021(42.9)$ & $3326(19.5)$ & 2.33 (2.05 to 2.66$)$ & $<0.001$ \\
\hline \multicolumn{5}{|l|}{ Marital status } \\
\hline Never married & $13464(34.0)$ & $1489(11.1)$ & ref. & \\
\hline Married/living with partner & $23008(58.0)$ & 3097 (13.5) & $1.13(1.04,1.22)$ & 0.003 \\
\hline Widowed/divorced/separated & $3174(8.0)$ & $542(17.1)$ & 1.15 (1.03 to 1.28$)$ & 0.01 \\
\hline \multicolumn{5}{|l|}{ Employment status } \\
\hline No & $15304(38.7)$ & 1529 (10.0) & ref. & \\
\hline Yes & $24240(61.3)$ & $3583(14.8)$ & $1.23(1.15$ to 1.31$)$ & $<0.001$ \\
\hline \multicolumn{5}{|l|}{ Pregnancy status } \\
\hline No & 36641 (92.4) & 4766 (13.0) & ref. & \\
\hline Yes & $3005(7.6)$ & $362(12.1)$ & $1.16(1.05$ to 1.29$)$ & 0.005 \\
\hline \multicolumn{5}{|l|}{ Breastfeeding status } \\
\hline No & $30737(77.5)$ & $4110(13.4)$ & ref. & \\
\hline Yes & 8909 (22.5) & $1018(11.4)$ & 1.09 (1.01 to 1.17$)$ & 0.02 \\
\hline \multicolumn{5}{|l|}{ Number of living children } \\
\hline None & $10949(27.6)$ & 895 (8.2) & ref. & \\
\hline $1-4$ & $22360(56.4)$ & $3637(16.3)$ & 1.55 (1.40 to 1.73$)$ & $<0.001$ \\
\hline More than 4 & $6337(16.0)$ & $596(9.4)$ & 1.30 (1.13 to 1.50$)$ & 0.003 \\
\hline \multicolumn{5}{|l|}{ Household has radio } \\
\hline No & $12589(31.8)$ & $1274(10.1)$ & ref. & \\
\hline Yes & $27038(68.2)$ & $3847(14.2)$ & $1.04(0.97$ to 1.11$)$ & 0.25 \\
\hline \multicolumn{5}{|l|}{ Household has television } \\
\hline No & $23280(58.8)$ & $2112(9.1)$ & ref. & \\
\hline Yes & $16337(41.2)$ & $3013(18.4)$ & 1.17 (1.08 to 1.27$)$ & $<0.001$ \\
\hline \multicolumn{5}{|c|}{ Visited healthcare facility last 12 months } \\
\hline No & $15985(40.3)$ & $1594(10.0)$ & ref. & \\
\hline
\end{tabular}

Continued 


\begin{tabular}{llllll}
\hline & All participants & & $\begin{array}{l}\text { Breast cancer } \\
\text { screening }\end{array}$ & & \multicolumn{2}{l}{$\begin{array}{l}\text { Multivariable-adjusted } \\
\text { analysis }\end{array}$} \\
\cline { 2 - 3 } Characteristic & $\mathbf{N}(\%)$ & $\mathbf{N}(\%)$ & aPR (95\% Cl) & P value \\
\hline Yes & $23642(59.7)$ & $3528(14.9)$ & $1.37(1.28$ to 1.45$)$ & $<0.001$ \\
\hline
\end{tabular}

Model fully adjusted for country, health insurance coverage pregnancy status, breastfeeding status, age, education status, marital status, wealth index status, place of residence, employment status, number of living children, household having a radio or television and visited healthcare facility in the last 12 months. ref., reference.

considered as part of a physical examination because it provides an opportunity to discuss and educate women about their breast health. ${ }^{19}$ Our data underscore the need to deploy more efforts in the field to encourage and promote early screening, which could have significant public health impacts in these resource-poor countries.

The multivariable analysis of four combined countries showed that factors that were independently associated with breast cancer screening were country of residence, health insurance coverage, age, wealth index status, education level, marital status, owning a television, place of residence, employment status, pregnancy status, breastfeeding status, visited healthcare facility in the last 12 months and the number of living children. The positive association between increased age and breast cancer screening could be explained by older women knowing the benefits of screening for preventing breast cancer. In addition, older women are more vulnerable to breast cancer than younger women with a known higher likelihood of having the disease. ${ }^{45}$ This finding is consistent with previous studies that also found older women were more likely to be screened for breast cancer than younger women. ${ }^{62}$ As one would expect, having health insurance coverage was positively associated with breast cancer screening, a finding that is consistent with other studies. ${ }^{622}$ This could be because health insurance coverage provides an opportunity for women to undergo preventive care services at no additional cost. Increased education was positively associated with higher breast cancer screening in this study even in places where the majority of women are undereducated. Educated women may be more informed about their health and adverse outcomes of breast cancer compared with uneducated women. ${ }^{46}$ This highlights the need for more educational-based programmes about breast cancer to promote screening. Our finding is in accordance with previous studies that also indicated that higher educated women were more likely to be screened for breast cancer than those with lower-level education. ${ }^{62}$ We found that family wealth status was positively associated with breast cancer screening during our study period. Wealthy women have stronger financial means to purchase health insurance coverage, which could lead to an increase in preventive care services. Moreover, because of poverty, women in the lowest economic status may not prioritise preventive care behaviours including breast cancer screening over the daily necessities of feeding the families. ${ }^{43} 48$ The negative association between breast cancer screening and living in rural areas was not surprising and could be due to disparities in access to healthcare services and lack of hospitals and other healthcare facilities. ${ }^{22} 4950$ Interestingly, our study found that ownership of television was positively associated with breast cancer screening, indicating a higher possibility of exposure to mass media. A previous study indicated that most women in Kenya preferred to be alerted about screening activities through messages broadcast by local radio stations. ${ }^{39}$ Furthermore, this finding aligned with another previous study that also found that exposure to mass media was significantly associated with breast cancer screening in SSA. ${ }^{6}$ Mass media is the most effective way to spread health messages in low resource settings, such as SSA. ${ }^{51}$ Furthermore, we found that women who visited healthcare facilities within the last 12 months were likely to undergo breast cancer screening.

\section{Study strengths and limitations}

Our study has several strengths. To the best of our knowledge, this is one of a few studies to investigate the prevalence and determinants of breast cancer screening across multiple SSA countries, which makes evaluation powered and diverse enough to provide a strong conclusion on the disease burden in SSA. The findings from this study will assist in improving the uptake of breast cancer screening counselling practices and interventions in these countries and the entire SSA regions. Notwithstanding, our study has a few limitations that should be noted. First, the cross-sectional nature of the survey does not allow for the determination of temporal relationships and outcome measures. Second, this study was limited to only 4 of the 48 countries in SSA. Third, DHS data for breast cancer screening questions for most countries were limited to women of reproductive age (15-49 years old) and about half of our participants were under the age of 30 years, an age group not recommended for mammography screening. However, since the survey question on breast cancer recorded only a binary response (yes/no) and was not modified for age groups, we were unable to determine which screening method was used by all women. Thus, we did not exclude women younger than 30 to get a sense of how much screening occurs in this age group in SSA. In addition, information on why women were screened 
such as due to symptoms, part of prenatal care or routine interaction with healthcare providers were not included in the data. Fourth, because the question of breast cancer screening for some countries was broader, we do not know which screening methods respondent women have received prior to the survey. Despite these limitations, this study provides useful information regarding breast cancer screening rates and associated factors among women of reproductive age for the first time in four SSA countries.

\section{CONCLUSIONS AND RECOMMENDATIONS}

The rate of breast cancer screening in SSA is very low, which indicates the need for targeted intervention to reduce the burden of breast cancer and improve survivorship. The findings from our study showed great heterogeneity in breast cancer screening across SSA countries and related to women's demographic and personal characteristics. Having health insurance coverage, being older, higher socioeconomic status, higher education and possession of television were some of the leading factors independently and positively associated with breast cancer screening. The findings highlight an urgent need for intervention targeting to encourage screening behaviours for detecting breast cancer in this region. The positive association between health insurance and breast cancer indicated that universal health insurance policy may be effective in increasing the uptake of breast cancer screening in SSA. Intensive health education and awareness campaigns through partnering with local radio stations should be conducted to educate women about the benefits of breast cancer screening.

Acknowledgements The authors thank the DHS program implemented by ICF for granting free access to the original data. The authors also thank Kani Dembele for her assistance with the literature search.

Contributors Study design; data analysis and interpretation and writing manuscript first draft: DB. Data acquisition: DB. Authors PS, MM, EA, YY, RC, BD, $\mathrm{CBT}, \mathrm{BK}, \mathrm{YK}, \mathrm{GD}, \mathrm{ED}$ and $\mathrm{HD}$ edited and commented on the draft of the manuscript. All authors have read and approved the final manuscript.

Funding The authors have not declared a specific grant for this research from any funding agency in the public, commercial or not-for-profit sectors.

Map disclaimer The depiction of boundaries on this map does not imply the expression of any opinion whatsoever on the part of BMJ (or any member of its group) concerning the legal status of any country, territory, jurisdiction or area or of its authorities. This map is provided without any warranty of any kind, either express or implied.

Competing interests None declared.

Patient consent for publication Not required.

Provenance and peer review Not commissioned; externally peer reviewed.

Data availability statement Data for this study are available online (https:// dhsprogram.com/Data/).

Open access This is an open access article distributed in accordance with the Creative Commons Attribution Non Commercial (CC BY-NC 4.0) license, which permits others to distribute, remix, adapt, build upon this work non-commercially, and license their derivative works on different terms, provided the original work is properly cited, appropriate credit is given, any changes made indicated, and the use is non-commercial. See: http://creativecommons.org/licenses/by-nc/4.0/.

ORCID iDs

Djibril M Ba http://orcid.org/0000-0002-5598-636X
Paddy Ssentongo http://orcid.org/0000-0003-1565-5731

Yanxu Yang http://orcid.org/0000-0003-0121-4951

\section{REFERENCES}

1 Bray F, Ferlay J, Soerjomataram I, et al. Global cancer statistics 2018: GLOBOCAN estimates of incidence and mortality worldwide for 36 cancers in 185 countries. CA Cancer J Clin 2018;68:394-424.

2 World Health Organization. Latest world cancer statistics. Geneva: International Agency for Research in Cancer, 2013.

3 International Agency for Research on Cancer. Globacon 2018: estimated cancer incidence, mortality and prevalence worldwide in 2018. Available: http://gco.iarc.fr/today/data/factsheets/populations/ 900-world-fact-sheets.pdf [Accessed 3 Apr 2020].

4 International Agency for Research on Cancer. Globacon 2018: estimated cancer incidence, mortality and prevalence worldwide in 2018. Available: $\mathrm{http} / / / \mathrm{gco}$.iarc.fr/today/data/factsheets/populations/ 903-africa-fact-sheets.pdf [Accessed 3 Apr 2020].

5 Cumber SN, Nchanji KN, Tsoka-Gwegweni JM. Breast cancer among women in sub-Saharan Africa: prevalence and a situational analysis. Southern African Journal of Gynaecological Oncology 2017;9:35-7.

6 Kangmennaang J, Mkandawire P, Luginaah I. Breast cancer screening among women in Namibia: explaining the effect of health insurance coverage and access to information on screening behaviours. Glob Health Promot 2019;26:50-61.

7 Faronbi JO, Abolade J. Breast self examination practices among female secondary school teachers in a rural community in Oyo state, Nigeria. Open J Nurs 2012;02:111-5.

8 Black E, Richmond R. Improving early detection of breast cancer in sub-Saharan Africa: why mammography may not be the way forward. Global Health 2019;15:3-4.

9 Ssentongo P, Lewcun JA, Candela X, et al. Regional, racial, gender, and tumor biology disparities in breast cancer survival rates in Africa: a systematic review and meta-analysis. PLOS One 2019;14:e0225039.

10 US Preventive Services Task Force. Screening for breast cancer: U.S. preventive services Task force recommendation statement. Ann Intern Med 2009;151:716-26.

11 Berry DA, Cronin KA, Plevritis SK, et al. Effect of screening and adjuvant therapy on mortality from breast cancer. $N$ Engl $J$ Med 2005;353:1784-92.

12 Lipschitz S. Screening mammography with special reference to guidelines in South Africa. SA J Radiol 2018;22:1370-1.

13 Gabe R, Duffy SW. Evaluation of service screening mammography in practice: the impact on breast cancer mortality. Ann Oncol 2005;16 Suppl 2:ii153-62.

14 Nelson HD, Tyne K, Naik A. Screening for breast cancer: an update for the U.S. preventive services Task force. Ann Intern Med 2009;151:727-42.

15 Brinton LA, Figueroa JD, Awuah B, et al. Breast cancer in subSaharan Africa: opportunities for prevention. Breast Cancer Res Treat 2014;144:467-78.

16 Mutebi M, Edge J. Stigma, survivorship and solutions: addressing the challenges of living with breast cancer in low-resource areas. $S$ Afr Med J 2014;104:383.

17 Enow OGE, Ndom P, Doh AS. Current cancer incidence and trends in Yaoundé, Cameroon. Gastroenterol Heptol Reports 2012;1:58-63.

18 Omaka-Amari LN, llo CI, Nwimo IO, et al. Demographic differences in the knowledge of breast cancer among women in Ebonyi state, Nigeria. IJNMH 2015;1:18-27.

19 Ministry of Health, Kenya. Kenya National cancer screening guidelines Nairobi 2018.

20 Othieno-Abinya NA, Musibi A, Nyongesa C, et al. Report on breast cancer care (BRECC) registry at the Kenyatta national Hospital, Nairobi, Kenya. Journal of Clinical Oncology 2018;36:e12546-67.

21 Gebremariam A, Addissie A, Worku A, et al. Time intervals experienced between first symptom recognition and pathologic diagnosis of breast cancer in Addis Ababa, Ethiopia: a crosssectional study. BMJ Open 2019;9:e032228.

22 Antabe R, Kansanga M, Sano Y, et al. Utilization of breast cancer screening in Kenya: what are the determinants? BMC Health Serv Res 2020;20:228-9.

23 Rutstein S, Rojas G. Guide to DHS statistics. demographic and health surveys. Calverton, Maryland ORCMacro; 2003.

24 Macro International Inc. Measure DHS: demographic and healthsurveys. available from. Available: http://www.measuredhs. $\mathrm{com} /$ countries/browse_country.cfm?selected=2

25 Mishra V, Vaessen M, Boerma JT, et al. HIV testing in national population-based surveys: experience from the demographic and health surveys. Bull World Health Organ 2006;84:537-45. 
26 Macro International Inc. Measure DHS: demographic and healthsurveys. Available: https://dhsprogram.com/What-We-Do/ Protecting-the-Privacy-of-DHS-Survey-Respondents.cfm [Accessed 13 Jun 2020].

27 Viens L, Perin D, Senkomago V, et al. Questions about cervical and breast cancer screening knowledge, practice, and outcomes: a review of demographic and health surveys. $J$ Womens Health 2017;26:403-12.

28 Macro International Inc. Measure DHS: demographic and healthsurveys. Available: https://dhsprogram.com/What-We-Do/ Questionnaires.cfm [Accessed 13 May 2019].

29 Lunani LL, Abaasa A, Omosa-Manyonyi G. Prevalence and factors associated with contraceptive use among Kenyan women aged 1549 years. AIDS Behav 2018;22:125-30.

30 Titilayo A, Palamuleni ME, Olaoye-Oyesola JO, et al. Religious perceptions and attitudes of men towards discontinuation of female genital cutting in Nigeria: evidence from the 2013 Nigeria demographic and health survey. Afr J Reprod Health 2018;22:20-8.

$31 \mathrm{Ba} \mathrm{DM}$, Ssentongo $\mathrm{P}$, Kjerulff $\mathrm{KH}$, et al. Adherence to iron supplementation in 22 sub-Saharan African countries and associated factors among pregnant women: a large population-based study. Curr Dev Nutr 2019;3:nzz120.

32 Macro International Inc. Measure DHS: demographic and healthsurveys. using datasets for analysis. Available: https://www. dhsprogram.com/data/Using-Datasets-for-Analysis.cfm [Accessed 13 Jun 2020].

33 Spiegelman D, Hertzmark E. Easy SAS calculations for risk or prevalence ratios and differences. Am J Epidemiol 2005;162:199-200.

34 Kisuya J, Wachira J, Busakhala N, et al. Impact of an educational intervention on breast cancer knowledge in Western Kenya. Health Educ Res 2015;30:786-96.

35 Corbex M, Burton R, Sancho-Garnier H. Breast cancer early detection methods for low and middle income countries, a review of the evidence. Breast 2012;21:428-34.

36 Cancer Association of South Africa (CANSA). Fact sheet on effective radiation received from routine mammography. Available: https:// www.cansa.org.za/files/2017/04/Fact-Sheet-Effective-RadiationReceived-from-Routine-Mammography-April-2017.pdf [Accessed 20 Jun 2020].

37 Sankaranarayanan R, Ramadas K, Thara S, et al. Clinical breast examination: preliminary results from a cluster randomized controlled trial in India. J Nat/ Cancer Inst 2011;103:1476-80.
38 Pisani P, Parkin DM, Ngelangel C, et al. Outcome of screening by clinical examination of the breast in a trial in the Philippines. Int $J$ Cancer 2006;118:149-54.

39 Busakhala NW, Chite FA, Wachira J, et al. Screening by clinical breast examination in Western Kenya: who comes? J Glob Oncol 2016;2:114-22.

40 Memorial Sloan Kettering Cancer Center. Breast cancer screening guidelines. Available: https://www.mskcc.org/cancer-care/types/ breast/mammograms-breast-exams/screening-guidelines-breast [Accessed 20 Jun 2020].

41 Curado MP, Edwards B, Shin HR, et al. Cancer incidence in five continents. Vol. IX. Lyon: France International Agency for Research on Cancer, 2007. ISBN: IARC Scientific Publications No. 160

42 National cancer registry program of India, consolidated report of population based cancer registries 2001-2004 Bangalore, Indialndian Council of medical research, 2006. Available: http://www.icmr.nic.in/ ncrp/report_pop_2001-04/cancer_p_based.htm [Accessed 20 Jun 2020].

43 Akinyemiju TF. Socio-Economic and health access determinants of breast and cervical cancer screening in low-income countries: analysis of the world health survey. PLoS One 2012;7:e48834.

44 Abuidris DO, Elsheikh A, Ali M, et al. Breast-Cancer screening with trained volunteers in a rural area of Sudan: a pilot study. Lancet Oncol 2013;14:363-70.

45 Korir A, Okerosi N, Ronoh V, et al. Incidence of cancer in Nairobi, Kenya (2004-2008). Int J Cancer 2015;137:2053-9.

46 Ochako R, Fotso J-C, Ikamari L, et al. Utilization of maternal health services among young women in Kenya: insights from the Kenya demographic and health survey, 2003. BMC Pregnancy Childbirth 2011;11:1.

47 Strother RM, Asirwa FC, Busakhala NB, et al. The evolution of comprehensive cancer care in Western Kenya. $J$ Cancer Policy 2013;1:e25-30.

48 Magadi MA, Madise NJ, Rodrigues RN. Frequency and timing of antenatal care in Kenya: explaining the variations between women of different communities. Soc Sci Med 2000;51:551-61.

49 Hongoro C, McPake B. How to bridge the gap in human resources for health. Lancet 2004;364:1451-6.

50 Bishwajit G, Kpoghomou M-A. Urban-Rural differentials in the uptake of mammography and cervical cancer screening in Kenya. $J$ Cancer Policy 2017;12:43-8 https://doi.org/

51 Ba DM, Ssentongo P, Agbese E, et al. Prevalence and predictors of contraceptive use among women of reproductive age in 17 sub-Saharan African countries: a large population-based study. Sex Reprod Healthc 2019;21:26-32. 